\title{
Treinamentos corporativos na perspectiva da prática social
}

\section{Corporative training through the social practice perspective}

\author{
Rafaella Cristina Campos ${ }^{1}$ \\ Valéria da Glória Pereira Brito ${ }^{2}$
}

Resumo: Objetiva-se compreender como se traduz nas ações cotidianas as práticas de aprendizagem dos agentes diante dos treinamentos corporativos. A aprendizagem organizacional, na perspectiva da teoria da prática é mais que um processo de ensino-aprendizagem e sim de subjetivação e (re)significação cotidiana que legitima as ações organizacionais correlacionandoas com as práticas cotidianas. A metodologia é qualitativa de estudo de caso, aplicando doze questionários semiabertos em uma empresa familiar. Conclui-se que há movimento de resistência, o que integra a textura organizacional, a formação do knowing individual, a influência no knowledge grupal, gerando consciência coletiva de que as práticas cotidianas não são coerentes com as ações de treinamento corporativo. Entretanto não há evidencias de um embate direto, denotando que o poder e a dominância cultural são dinâmicas relacionais, que interferem no desenvolvimento de ações inovadoras no contexto organizacional, indo na contramão da intencionalidade das ações de aprendizagem organizacional como pensadas pela organização.

Palavras-Chave: Treinamentos Corporativos; Práticas Cotidianas; Aprendizagem.

\footnotetext{
1 Doutoranda em Ciências Sociais Aplicadas pela Universidade Federal de Lavras, no Departamento de Administração e Economia, junto do Programa de Pós-Graduação em Administração. Mestre Ciências Sociais Aplicadas pela Universidade Federal de Lavras, no Departamento de Administração e Economia. Bacharela em Psicologia pelo Centro Universitário de Lavras. Professora de ensino superior na Faculdade Presbiteriana Gammon. E-mail: rafaella_ccampos@hotmail.com

${ }^{2}$ Professora Associada do Departamento de Gestão Agroindustrial da Universidade Federal de Lavras, possui graduação em Agronomia pela Escola Superior de Agricultura de Lavras, mestrado em Administração Organizações e Recursos Humanos pela Universidade Federal de Minas Gerais e doutorado em Administração pela Universidade Federal de Minas Gerais. E-mail: vgpbrito@gmail.com
}

\begin{tabular}{l|l|l|l|l|l|} 
(C) Revista SCRIBES & Viçosa, $M G$ & v. 1 & n. 1 & Julho/2020 & ISSN 2675-4401
\end{tabular}


Abstract: The main goal of this article is to understand how agents' learning practices are translated into daily actions in the face of corporate training. Organizational learning, from the perspective of theory of practice, is more than a teaching-learning process, but subjectivity and everyday (re) meaning that legitimizes organizational actions by correlating them with everyday practices. The methodology is a qualitative case study, applying twelve semi-open questionnaires in a family business. It is concluded that there is a resistance movement, which integrates the organizational texture, the formation of individual knowing, the influence on group knowledge, generating collective awareness that the daily practices are not coherent with the corporate training actions. However, there is no evidence of a direct clash, denoting that power and cultural dominance are relational dynamics, which interfere in the development of innovative actions in the organizational context, going against the intentionality of organizational learning actions as thought by the organization.

Keywords: Corporative Training; Daily Practices; Learning.

\section{Considerações iniciais}

Os "componentes" mais complexos em uma organização são as pessoas, consistindo na totalidade do quadro de agentes de uma empresa que, sob a perspectiva empresarial, têm como objetivo final promover o lucro pelo alcance das metas, com excelência dos processos e produtos. Tanto para alcance das metas, quanto para capacitação, é necessário não só que a experiência prévia dos agentes, mas também que a empresa, em suas funções gerenciais, proporcione conhecimento e ensinamento, que são realizados por meio dos treinamentos corporativos (Teixeira \& Poupadiuk, 2003; Jesus \& Mourão, 2012; Mourão \& Martins, 2009).

Os treinamentos corporativos consistem, portanto, na capacitação dos agentes de qualquer posição hierárquica, possibilitando a relação de ensino e aprendizagem, que promova melhoras nos processos da empresa, de acordo com seu foco produtivo, processual e (ou) gerencial (Cavalcante, 2006; Lacerda \& Abbad, 2003; Ruas \& Antonello, 2003). 
Resumidamente, os treinamentos são construídos para desenvolver ações corretivas ou normativas, aprimorando alguma técnica de trabalho ou comportamento desejável nas organizações. Nota-se que, na corrente dominante, os treinamentos são estudados sob a ótica funcionalista, que busca sempre relações de causalidade ou custo-benefício. Desta forma, os treinamentos corporativos buscam a eficiência empresarial por meio da capacitação de seus quadros. Entretanto, novas abordagens buscam suprir lacunas trazendo novos elementos que contribuem para os estudos da aprendizagem sob a perspectiva sociológica, como, por exemplo, Gherardi (1999, 2000, 2003, 2006).

Para esta autora, as práticas permitem a aprendizagem e a organização de um grupo, contribuindo para a construção e identificação das particularidades deste grupo pelo processo de formação da textura organizacional. Por textura organizacional a autora define a relação existente entre os elementos humanos e não humanos que ao se imbricarem, produzem as práticas que representam o mosaico que constitui uma organização.

Neste sentido, ao se considerar as práticas como um artefato que permite ou causa a aprendizagem, constituindo deste modo a organização, pode-se dizer que esta mudança de foco configura um novo paradigma cuja ontologia e epistemologia apresentam uma possibilidade para colaborar com as pesquisas em estudos organizacionais, especialmente os estudos sobre aprendizagem organizacional (Bispo, 2013; Reckwitz, 2016).

Tendo em vista que o resultado esperado da relação ensino-aprendizagem que a organização almeja alcançar por meio dos treinamentos corporativos deve passar pela subjetividade individual e coletiva dos agentes para fazer-se presente e efetivamente ligado ao cotidiano de trabalho, questiona-se: Como se dão, nas ações cotidianas dos agentes, as práticas de aprendizagem, transmitidas por meio dos treinamentos corporativos?

O objetivo principal deste artigo é compreender como se traduzem nas ações cotidianas as práticas de aprendizagem dos agentes diante dos treinamentos corporativos.

Justifica-se a execução deste artigo pela sua contribuição prática, uma vez que investimentos e exigências em treinamentos corporativos são crescentes e não há evidência de estudos que busquem a compreensão no cotidiano de como o treinamento corporativo se traduz

\begin{tabular}{|c|c|c|c|c|c|}
\hline () Revista SCRIBES & Viçosa, $M G$ & v. 1 & n. 1 & Julho/2020 & ISSN 2675-4401 \\
\hline
\end{tabular}


nas práticas de aprendizagem. Considera-se também a contribuição teórica deste trabalho, que busca discutir e alinhar a contextualização atual sobre treinamentos corporativos, que na literatura é escassa em discussão e farta em manuais no segmento de pop management, bem como na perspectiva da prática social, que é emergente nos estudos sobre o tema. Neste sentido, este artigo contribui, de forma incipiente, com os estudos que começam a adotar a abordagem da prática na gestão do conhecimento.

\section{Treinamentos corporativos como aprendizagem: Gestão do conhecimento sob a} ótica da prática social.

A aprendizagem organizacional é um tema recorrente que apresenta distintas abordagens ontológicas e epistemológicas, caracterizando-se como um campo multiparadigmático (Antonello \& Godoy, 2010; Bispo, 2013).

Uma dessas abordagens refere-se à visão sociológica da aprendizagem nas organizações, na qual o ambiente social é o espaço onde ocorrem os processos de aprendizagem e a geração do conhecimento (Gherardi, Nicolini, \& Odella, 1998; Gherardi \& Nicolini, 2001; Bispo, 2013; Hogde, 2014). Sob este prisma, a abordagem sociológica da aprendizagem considera que as pessoas só aprendem quando há interação em determinado espaço social, contrapondo-se à perspectiva cognitivista que considera que a aprendizagem ocorre nas mentes das pessoas. Assim sendo, as pessoas constroem a aprendizagem por meio da dinâmica de negociação e produção dos significados das palavras, ações, situações e artefatos materiais estabelecida em grupos. Nesta direção, a abordagem da aprendizagem nas organizações é considerada numa perspectiva social construtivista. Nesta abordagem, parte-se do pressuposto de que a linguagem é o principal elemento de qualquer processo de aprendizagem e que toda aprendizagem está sempre associada a alguma prática (Gherardi et al., 1998; Bispo, 2013).

Neste sentido, discute-se que a prática é o modo para a compreensão e explicação da aprendizagem em grupos. A evolução e aprofundamento do conceito de "aprendizagem organizacional" é paulatinamente substituído na obra de Gherardi pela teoria baseada na prática, 
que traz como principais fundamentos o knowing, a participação, a interação, a linguagem e as metáforas (Gherardi, 2002, 2006, 2012; Bispo, 2013). Assim sendo, o knowing é considerado como o processo que resulta no knowledge (conhecimento), de tal modo que o conhecimento é uma forma institucionalizada do knowing (Gherardi, 2002, 2006, 2012).

Dessa forma, a organização não é um espaço de acúmulo de informações e conhecimento, considerando que tanto o conhecimento quanto a aprendizagem são permanentemente construídos e reconstruídos pelas práticas cotidianas de um grupo em dado contexto. As práticas então formam a rede de relacionamentos e a própria organização. Ao deslocar o lugar do conhecimento e da aprendizagem para a prática, a ênfase recai na teoria social da ação. Esse deslocamento considera que a atividade e a passividade, o cognitivo, o emocional, o mental e a percepção sensorial são como partes, "pedaços" da construção social do conhecimento e do mundo social nos quais as práticas assumem significados e a tessitura deste mundo (Gherardi, 2001).

Há que se considerar também que as práticas devem ser situadas, ou seja, contextualizadas no tempo e no espaço do grupo de pessoas que as constroem coletivamente. Do ponto de vista metodológico, a apreensão do knowing deve ser com uma prática situada que possibilite o estudo de onde e como o conhecimento é socialmente construído, considerando atividade e passividade (Bispo, 2013).

Nota-se então que a aprendizagem, sob a perspectiva da prática e no contexto organizacional, não é meramente a absorção e repetição com restrição conteudista. A aprendizagem entendida como prática social consiste na formação, estruturação e sedimentação de densidade relacional, que mensura o conhecimento tangível por parte das práticas e relações intangíveis do trabalho cotidiano. Portanto, no contexto dos treinamentos corporativos, mais do que evidenciar por meio de resultados, se houve absorção do conteúdo transmito no momento do treinamento, é necessário compreender se houve internalização do (dos) assunto (assuntos) abordado (abordados) e também a formação de uma consciência coletiva a respeito da aprendizagem que deve ser vivida nas práticas cotidianas, tendo em vista a perspectiva da prática social. 


\section{Procedimentos metodológicos}

O objetivo principal deste artigo é compreender como se traduz nas ações cotidianas as práticas de aprendizagem dos agentes diante dos treinamentos corporativos.

Para tanto, opta-se pela metodologia qualitativa de pesquisa, que consiste na observação, captação e análise de conteúdo descritivo, com pouca preocupação quanto à generalização, focando na especificidade do fenômeno estudado, sem levar em conta os aspectos numéricos que envolvam o evento de estudo (Godoy, 1995).

Partindo da natureza qualitativa, define-se como método o estudo de caso, definido como uma análise de um fenômeno focal, com sujeição à ocorrência múltipla, mas ainda não comprovada (Pereira, Godoy, \& Terçariol, 2009).

A organização que participa deste estudo foi selecionada por conveniência. É uma empresa familiar do segmento de transporte e logística. A empresa está em ascensão no Brasil (demonstra crescimento nos investimentos e capital de giro nos negócios da organização) e há certificação da ISO vigente, ou seja, desta forma, sabe-se que há exigência de vigência de treinamentos rotineiros na organização, bem como interesse direto da mesma em proporcionar educação corporativa, uma vez tendo seus processos e produtos com certificação de qualidade.

A coleta de dados foi através de um questionário semiaberto que teve como respondentes doze sujeitos, contemplando todos os doze setores em que a empresa subdivide seus processos. Cada participante foi selecionado por meio de conveniência. Foi definido o questionário como instrumento de coleta de dados, uma vez que a empresa determinou curto prazo de tempo para captação dos dados para esta pesquisa, então o questionário mostrou-se mais eficaz e assertivo, dado o tempo disponibilizado. O questionário foi preenchido individualmente, na presença e com auxílio dos pesquisadores, após a assinatura do Termo de Consentimento Livre e Esclarecido (T.C.L.E.), que permite seguridade das informações e sigilo de identidade, da organização e dos respondentes envolvidos. 
A análise dos dados foi baseada na análise de conteúdo, que consiste "em um conjunto de técnicas de análise das comunicações, que visa obter por segmentos sistemáticos e objetivos de descrição do conteúdo, indicadores e conhecimentos relativos às variáveis que estão sendo estudadas" (Bardin, 1977, p. 31).

Após a descrição dos procedimentos metodológicos que guiaram a construção deste artigo, segue abaixo as análises dos dados.

\section{Reflexão e discussão dos dados: A construção coletiva das práticas cotidianas e de} aprendizagem

A interpretação dos dados visa a perpassar os conceitos básicos da aprendizagem organizacional como prática, buscando compreender como é traduzido nas práticas cotidianas o que foi apreendido nas ações programadas na educação corporativa. Sendo assim, com base na literatura, a discussão dos dados vai permear os conceitos de identificação, textura organizacional, knowing e knowledge.

De acordo com os achados sobre aprendizagem organizacional, tendo como pano de fundo a teoria da prática, a identificação consiste na internalização subjetiva do agente de ações promovidas pela organização (Flach \& Antonello,2011; Yakhlef \& Essén, 2012).

Quando se fala de aprendizagem, não estão aqui referenciadas somente as ações que diretamente são proporcionadas por meio de cursos, treinamentos e demais atividades de preparação corretiva e (ou) normativa. Está aqui englobada como identificação toda a internalização subjetiva que é feita pelo agente, por um processo sistemático que leva em conta as relações e ações afetivas e objetivas do (no) trabalho, que vão predizer da conduta e engajamento do agente perante a organização.

Há jargões, reforçados por slogans e campanhas, e ações, por meio dos treinamentos e diversas atividades de educação corporativa, que são comuns e dos quais as organizações lançam mão a fim de buscar o engajamento e a identificação dos agentes. Estas ações estão arraigadas na cultura organizacional e há evidências de que isto produz feito considerável. Expressões como 
"vestir a camisa" e "dar o sangue", foram expressas pelos agentes participantes da pesquisa, identificados por números de 1 a 11: "É muito importante para quem faz, além de saber o motivo pelo qual está executando seu trabalho, qual o conceito e o porquê ele deve fazer daquela forma ou até mesmo alterar sua rotina com base em conceitos alinhados à técnica. Acredito que após os treinamentos dos últimos anos, os colaboradores que passaram por esses treinamentos tem outra cabeça para o trabalho" (Entrevista com Agente 1).

Ao mesmo tempo, nota-se que os agentes não estão constantemente imersos numa lógica de dominação cultural da empresa. Evidência disso é a resistência apresentada em diversas atividades de treinamento, que, segundo os agentes, foram ineficazes na aplicabilidade cotidiana: "Acredito que tem treinamento que é colocado para nós simplesmente porque tem que cumprir meta. Tem engenheiro que nem pergunta o que a gente quer com os treinamentos. $\mathrm{E}$ tem engenheiro que aplica treinamento sem noção do que acontece aqui embaixo [referindo-se ao pátio]. Acho que assim fica fácil definir tema de treinamento, mas a gente, mesmo sem gostar e sem usar, tem que ir" (Entrevista com Agente 1).

Após a aplicação do questionário, o Agente 5 disse: “Às vezes eles acham que é a gente é bobo, sabe? Esse negócio de colocar a gente mesmo para dar treinamento. Eles em aqui e fala 'ó, para valorizar o que vocês já sabem fulano vai dar o treinamento'. Tudo mentira! Isso aí é porque não teve dinheiro ou não teve tempo de achar alguém pra vir, sabe?! Aí a gente fica lá com umas horas extras no banco de horas e querem falar pra gente que isso é para o nosso reconhecimento, pro nosso crescimento? Isso é para tapar buraco, se fosse para o nosso bem eles iam pagar a fortuna que pagam pra quem vem de fora dar treinamento, concorda comigo?"

O primeiro e o segundo fragmento foram retirados do questionário de um mesmo agente, mostrando que as formas de resistência diante da cultura organizacional são por vezes sutis, menos evidentes, mas estão ali. Os dois fragmentos do Agente 1 mostram que identificação não consiste necessariamente na internalização de todo e qualquer aspecto do processo de aprendizagem na organização. É possível perceber que há nuances de coparticipação e de resistência e que estas contradições emergem na subjetividade do agente de forma 
complementar, de modo a torná-lo ciente do seu pertencimento à organização, mas, ao mesmo tempo, demonstra o embate entre sua consciência e sua identificação.

O terceiro relato foi extraído do diário de campo da pesquisa. Após responder o questionário, o Agente 5 relatou sua última experiência com treinamento corporativo, que neste caso foi na modalidade in house training, ou treinamento interno. Nesta modalidade, um colaborador que tem mais experiência ou detêm conhecimento específico acerca do tema do treinamento é selecionado para ser o instrutor e como remuneração recebe, frequentemente, horas extras registradas no banco de dados da empresa.

Observa-se com o relato que o agente percebe a diferença de investimento que a empresa faz em treinamentos com contratação interna e externa de instrutor. Isso, de acordo com o relato, compromete a internalização subjetiva de forma positiva com relação às ações de educação corporativa. Os relatos evidenciaram que nas práticas cotidianas os agentes percebem não só aquilo que circunda seus interesses diretos nas atividades do dia a dia e de educação corporativa como o treinamento em si, mas também estão atentos e perceptivos quanto às intenções secundárias da organização com relação ao desenvolvimento das atividades de treinamento com instrutor interno. O discurso, sendo uma forma de manifestação da ação e até mesmo a própria ação, mostra que a resistência pode não ser evidente, como quando ocorre uma renúncia ou recusa de se realizar o treinamento, mas está relacionada à intencionalidade das práticas cotidianas. Se a empresa, do ponto de vista dos agentes, programa um treinamento para "cumprir tabela ou a meta", os agentes também o fazem com o mesmo intuito, mesmo que as evidências nos discursos de ambas as partes não comprovem esta realidade.

O knowing torna-se evidente e sustentável com base nestes relatos, que demonstram formas de expressão, como o falar sem registrar no questionário, a evidência de que há dissonância em relação às ações de treinamento em detrimento das práticas cotidianas. O Agente 5 comprova que a linguagem e as opções de manifestação da mesma são coerentes com a forma com que a organização, mesmo que não intencionalmente, condiciona seus agentes a cumprirem as exigências da área estratégica, mas, ao mesmo tempo, responderem por meio do silêncio as verdades mascaradas, mas evidentes, sobre os motivos e resultados das ações de aprendizagem. 
Sendo assim, é possível perceber que não só a identificação com as práticas de aprendizagem ficam comprometidas, por conta da consciência coletiva silenciada sobre sua intencionalidade, mas também a textura organizacional, no sentido de inovação e melhoria, fica à mercê das lógicas de dominância cultural e legitimação nas práticas dos agentes: "A empresa possui uma excelente prática e política de treinamentos internos, porém, precisa reavaliar se realmente esses treinamentos trazem o retorno no desempenho laboral de cada colaborador. Além disso, os treinamentos mandatórios não possuem a mesma eficácia que os não obrigatórios. Geralmente, durante os treinamentos existe uma melhora, mas após isso a tendência é acomodar e tudo aquilo que foi desenvolvido tende a se perder" (Entrevista com Agente 11).

Segundo o Agente 7: "O que se vê é uma mobilização grande durante os treinamentos. Muitas vezes o erro está no acompanhamento/reciclagem. Os treinamentos são dados mas não existe uma cobrança/acompanhamento eficaz, inclusive que consiga mensurar esse benefício".

A textura organizacional consiste na correlação entre os elementos tácitos e tangíveis das ações de aprendizagem organizacional, ou seja, a textura organizacional consiste na ponte que o agente estabelece entre aquilo que lhe é ensinado e a forma que ele encontra para operacionalizar nas práticas cotidianas o que foi transmitido, tendo como aparato para fazer esta ligação o acúmulo de experiências dentro da empresa, mediando as demandas estratégicas e as especificidades do seu dia a dia.

Percebe-se pelos relatos acima que há distanciamento entre a forma como o treinamento é dado e como ele é encaixado na realidade cotidiana dos agentes que dele participam. Parece que a acomodação da textura organizacional fica a cargo dos agentes, ficando em segundo plano as exigências de cumprimento de atividades e metas que são demandadas pela organização, causando uma dissonância entre o trabalho prescrito e o trabalho real.

É possível perceber também o comprometimento das práticas inovadoras na textura organizacional. Se a inovação, no contexto da prática social, só é desenvolvida e efetivada a partir da percepção e ação do agente diante de sua necessidade de novas formas de conduta diante do seu cotidiano (Fuglsang \& Eide, 2012; Green \& Cluley, 2014), pelos relatos acima é possível identificar um efeito que merece ser mencionado. As atuais ações de aprendizagem 
organizacional proporcionada pelos treinamentos até então efetuados são impostas para os agentes, nem sempre em consonância com as demandas cotidianas. Portanto, as ações top down definidas pela organização acabam prejudicando o alcance de metas e exigências de nível estratégico, pois limitam a possibilidade de flexibilidade do agente que, de forma legítima, busca ações e comportamentos diferenciados para responder a questões recorrentes no cotidiano de trabalho.

Dito de outra forma, o knowledge fica regido e enrijecido pela burocracia, formalidade e exigências que partem do lado de fora das práticas cotidianas dos agentes, que precisam encontrar formas alternativas para operacionalizar no seu dia a dia o conhecimento necessário para lidar com suas atividades. Estas formas terminam por promover outro tipo de aprendizagem que a organização não leva em consideração ao planejar e definir os treinamentos.

\section{Considerações finais}

O objetivo principal deste artigo foi compreender como se traduz nas ações cotidianas as práticas de aprendizagem dos agentes diante dos treinamentos corporativos. Conclui-se que há movimento de resistência, o que compromete as metas planejadas pela organização, mas integram e imbricam a textura organizacional, a formação do knowing individual, que influencia no knowledge grupal, gerando uma consciência coletiva de que as práticas cotidianas não são coerentes com as ações planejadas de aprendizagem organizacional conforme pensado pela empresa. Entretanto, não há evidências de um embate direto, o que pode revelar que o poder e a dominância cultural e comportamental são dinâmicas relacionais, que interferem no desenvolvimento de ações inovadoras no contexto organizacional, indo na contramão da intencionalidade das ações de aprendizagem organizacional como definidas pela cúpula empresarial.

Reconhece-se as limitações deste estudo em uma única organização e num único contexto. Sugere-se para pesquisas futuras a realização de uma pesquisa que possa englobar mais agentes para compor o quadro de respondentes da pesquisa. A maior dificuldade para realização 
deste estudo foi a abertura de empresas que estivessem dispostas a permitir contato direto com os agentes para coleta de dados. Esta dificuldade evidencia o distanciamento entre prática cotidiana e ações educacionais de aprendizagem, desvelando que mesmo que a organização evite tocar nas questões mais profundas com relação aos seus agentes e suas políticas, não é possível uma blindagem de temas que são parte da realidade cotidiana de diversos agentes.

\section{Referências}

Antonello, C. S. \& Godoy, A. S. (2009). Uma agenda brasileira para os estudos em aprendizagem organizacional. Revista de Administração de Empresas. Vol. 49, n. 3. pp. 266-281.

Bardin, L. (1977) Análise de Conteúdo. Lisboa: Edições 70.

Bispo, M.S. (2013) Aprendizagem Organizacional Baseado no Conceito de Prática: Contribuições de Silvia Gherardi. Revista de Administração do Mackenzie. Vol.14. n. 6. São Paulo. pp. 132-161.

Bjerregaard, T. \& Klitmoller, A. (2016) A. Conflictual Practice Sharing in the MNC: a Theory of Practice Approach. Organization Studies. Vol37. N. 9. pp. 1271-1295.

Cavalcante, A. M. S. (2006) Treinamento como Ferramenta Estratégica para o Crescimento Organizacional. Revista Foco. Vol. 1. N. 1.

Flach L. \& Antonello, C.S. (2011) Organizações Culturais e a Aprendizagem Baseada em Práticas. Cadernos EBAPE.BR. Vol. 9. N. 1. Rio de Janeiro. pp. 156-176.

Fuglsang, L. \& Eide, D. (2012) The Experience Turn as “Bandwagon”: Understanding Network Formation and Innovation as Practice. European Urban and Regional Studies. Vol.20. n. 4. pp. 417-434.

Gherardi, S. (1999) A symbolic approach to competence development. Human Resource Development International. Vol. 2, n. 4. pp. 313-334

Gherardi, S. (2000) Where learning is: metaphors and situated learning in a planning group. Human Relations, Vol. 53, n. 8. pp. 1057-1080.

Gherardi, S. (2001) From organizational learning to practice-based knowing. Human Relations, Vol. 54, n. 1. pp. 131-139. 
Gherardi, S. (2003) Knowing as desiring: mythic knowledge and the knowledge journey in communities of practioners. Journal of Workplace Learning. Vol. 15, n. 7/8. pp. 352-358.

Gherardi, S. (2006) Organizational knowledge: the texture of workplace learning. Oxford: Blackwell Publishing.

Gherardi, S. (2012) How to conduct a practice-based study. Cheltenham: Edward Elgar.

Gherardi, S. \& Nicolini, D. (2001) The sociological foundations of organizational learning. In: DIERKES, M. et al. (Org.) Organizational learning and knowledge. Oxford: Oxford University Press, pp. 35-60.

Gherardi, S; Nicolini, D. \& Odella, F. (1998) Toward a social understanding of how people learn in organizations: the notion of situated curriculum. Management Learning. v. 29, n. 3. pp. 273-297.

Godoy, A. S. (1995) Introdução à pesquisa qualitativa e suas possibilidades. Revista de Administração de Empresas, São Paulo, Vol. 35. N. 2.

Green W. \& Cluley, R. (2014) The Field of Radical Innovation: Making Sense of Organizational Cultures and Radical Innovation. Industrial Marketing Management. Vol. 43. Special Edition. pp. 1343-1350.

Hodge, S. (2014) Transformative Learning as na "Inter-Practice" Phenomenon. Adult Education Quarterly. Vol.64. n. 2. pp. 165-191.

Jesus, A. M. \& Mourão, L. (2012) Conhecimento organizacional em escolas de governo: um estudo comparado. Revista de Administração Pública, Rio de Janeiro, v. 46, n. 4, ago.

Lacerda, E.R.M. \& Abbad, G. (2003) Impacto do Treinamento no Trabalho: Investigando variáveis motivacionais e organizacionais como suas preditoras. Revista de Administração Contemporânea, Curitiba, v. 7, n.4.

Mourão, L. \& Marins, J. (2009) Avaliação de Treinamento e Desenvolvimento nas organizações: Resultados relativos ao nível de aprendizagem. Revista Psicologia: Organizações e Trabalhos, v. 9, n. 2, jul./dez.

Pereira, L. T. K.; Godoy, D. M. A. \& Terçariol, D. (2009) Estudo de caso como procedimento de pesquisa científica: reflexão a partir da clínica fonoaudiológica. Psicologia: Reflexão $e$ Crítica, Porto Alegre, v. 22, n. 3.

Reckwitz, A. (2016) Toward a Theory of Social Practices: a Development in Culturalist Theorizing. European Journal of Social Theory. Vol.5. n. 2. pp. 243-263. 
Ruas, R. \& Antonello, C. S. (2003) Repensando os referenciais analíticos em aprendizagem organizacional: uma alternativa para análise multidimensional. Revista de Administração Contemporânea, Curitiba, v. 7, n. 3.

Teixeira, M. L. M. \& Popadiuk, S. (2003) Confiança e Desenvolvimento de Capital Intelectual: o que os empregados esperam de seus líderes? Revista de Administração Contemporanea, Curitiba, v. 7, n. 2.

Yakhlef, A \& Essén, A. (2012) Practice Innovation as Bodily Skills: the Exemple of Elderly Home Care Service Delivery. Organization. Vol.20. n. 6. pp. 881-903. 